\title{
A case report: venous sinus thrombosis in pregnancy
}

\author{
Abhilasha Singh ${ }^{1 *}$, Smiti Nanda ${ }^{2}$ \\ ${ }^{1}$ Department of Obstetrics and Gynaecology, Lady Hardinge Medical College, New Delhi, India \\ ${ }^{2}$ Department of Obstetrics and Gynaecology, Pandit B. D. Sharma PGIMS, Rohtak, Haryana, India
}

Received: 05 August 2017

Accepted: 04 September 2017

*Correspondence:

Dr. Abhilasha Singh,

E-mail: dr.abhilasha11@gmail.com

Copyright: $\odot$ the author(s), publisher and licensee Medip Academy. This is an open-access article distributed under the terms of the Creative Commons Attribution Non-Commercial License, which permits unrestricted non-commercial use, distribution, and reproduction in any medium, provided the original work is properly cited.

\begin{abstract}
Venous sinus thrombosis (VST) should be considered in the differential diagnosis of all unexplained central nervous system disorders of sudden onset. Etiological factors are subclinical forms of several common thrombophilic states occurring together, rather than the typical inherited and rare causes. Diagnosis is often missed because of the heterogeneity in clinical presentation and radiological investigation is essential for the diagnosis. Prognosis depends on the early detection. By correcting the cause, the complications can be prevented.
\end{abstract}

Keywords: Pregnancy, Thromboembolism, Thrombosis

\section{INTRODUCTION}

Venous sinus thrombosis (VST) is a rare form of venous thromboembolism (VTE). Venous sinus thrombosis represents almost $0.5-3 \%$ of all the types of stroke, affecting predominantly younger people with an estimated incidence for adults of 3-4 per million, and for children 7 per million..$^{1-3}$ The peripartum-associated VST has been established to be of 11.6 cases per 100000 deliveries. There is sex predominance; $75 \%$ of all VST patients are women, with a 3:1 ratio compared to men. ${ }^{4}$ Pregnancy and postpartum period are important risk factors for VST. Pregnancy itself is a thrombophilic state due to the changes in blood like increased factor VIII, fibrinogen, decreased protein $\mathrm{S}$, decreased fibrinolysis, obesity, caesarean section, immobilization and other mechanical and haemodynamic factors due to pregnant state. Coexisting hyperhomocysteinemia is very common due to malnutrition and consequent deficiency of folic acid. Besides the chance of tissue thromboplastin entering the blood from placenta due to injury, ischemia, or during delivery of fetus and the coexisting reactive thrombocytosis due to haemorrhage or iron deficiency state, all contribute to increased thrombotic tendency. During the last trimester of pregnancy and after delivery, the risk of cerebral venous sinus thrombosis is increased. ${ }^{5}$

\section{CASE REPORT}

Gravida 1 aged about 23 years with 35 weeks of gestation came in our institute with complain of right sided headache and diplopia for 1 day. She had spontaneous conception. There was $\mathrm{h} / \mathrm{o}$ intake of folic acid in first trimester, iron and calcium in $2^{\text {nd }}$ trimester. Ultrasonography was done in $1^{\text {st }}$ trimester $\mathrm{i} / \mathrm{v} / \mathrm{o}$ bleeding per vaginum but there was nothing significant. Level 2 scan was also normal. Her all 3 trimesters was uneventful. Patient was admitted and investigated for preeclampsia along with her vital and fatal monitoring. Her blood investigations were within normal limits. On fundus examination, there was mild hyperemic disc present. Emergency caesarean section was done in view of failed induction. Baby was healthy and alive. Intraoperative and postoperative period was uneventful. But headache and diplopia were still there. On examination ophthalmology consultant found right VI nerve palsy. He advised MRI brain and orbit. MRI brain and orbit was normal. So, we consulted neurologist who advised Magnetic Resonance Venography (MRV). Findings of MRV were suggestive of venous sinus thrombosis. After confirmation of diagnosis we started injection low molecular weight Heparin $60 \mathrm{mg}$ subcutaneous twice a day. After three to four days of 
heparin therapy or after the patient has shown steady improvement, warfarin is started at minimally effective doses, both are overlapped for two days and then heparin is withdrawn. Patient was relieved from her symptoms and discharged.

\section{DISCUSSION}

The incidence of VST is about 3-4 per millions of people each year. ${ }^{6,7}$ Women are affected 3 times more than men. Although majority of the patients gradually recover from acute episodes of VST, one in each eight patients suffers from either chronic disability or death. ${ }^{4}$ Lateral sinus thrombosis may present with increased intracranial pressure as the only presenting sign with associated headache. Patients with isolated intracranial hypertension have headache but no other neurologic symptoms, with the exception of diplopia due to sixth nerve palsy when the intracranial pressure is very high. Fundus examination may show papilloedema. Severe papilloedema can cause transient visual impairment, or if it is persistent and left untreated can cause even permanent blindness. Besides all these the clinical picture will usually be associated with the underlying disorder/s which contributed to the prothrombotic state. ${ }^{8,9}$ Although modern neuroimaging tools specially MRV has enhanced the early detection of VST. ${ }^{10}$ The clinical scenario of the present case initially seems to be a presentation of pre-eclampsia due to high blood pressure with headache and diplopia. The hypercoagulability state of pregnancy due to enhanced platelet adhesion and to increased coagulation factors could be an explanation for the augmented risk of VST. But subsequently further investigations revealed a case of VST. Guenther et al recommends that after the acute phase of VST, to use OA unless there is a clear contraindication and in cases of VST associated with a transient risk factor such as infection, trauma or pregnancy, a treatment period of 3 months is enough. Also recommend a suggest maintaining anticoagulation with an international normalized ratio (INR) of between 2.0 and 3.0. ${ }^{11}$ With appropriate anticoagulation therapy the patient promptly recovered and discharged in healthy condition.

\section{CONCLUSION}

The neurological manifestations of VST may be vague symptoms of vomiting, headache, seizures, stroke like features or manifestations of chronic intracranial hypertension like blurring of vision and women with pregnancy may present with pregnancy related complications. Thus, physicians should have a fair idea about the VST and their atypical presentations. Although venous thrombosis occurs 100 times less frequently than arterial thrombosis but we still should consider VST with strong suspicion in patients presenting with symptoms.

Funding: No funding sources

Conflict of interest: None declared

Ethical approval: Not required

\section{REFERENCES}

1. Bousser MG, Ferro JM. Cerebral venous thrombosis: An update. Lancet Neurol. 2007;6:162-70.

2. Ruiz-Sandoval JL, Chiquete E, Bañuelos-Becerra LJ, Torres-Anguiano C, González-Padilla C, Arauz A, et al. Cerebral venous thrombosis in a Mexican multicenter registry of acute cerebrovascular disease: The RENAMEVASC study. J Stroke Cerebrovasc Dis. 2012;21:395-400.

3. Stam J. Thrombosis of the cerebral veins and sinuses. N Eng J Med. 2005;352:1791-8.

4. Ferro JM, Canhão $\mathrm{P}$, Stam J, Bousser MG, Barinagarrementeria F. Prognosis of cerebral vein and dural sinus thrombosis: results of the International Study on Cerebral Vein and Dural Sinus Thrombosis (ISCVT). Stroke. 2004;35:664-70.

5. Coutinho JM, Ferro JM, Canhão P, Barinagarrementeria F, Cantú C, Bousser MG, et al. Cerebral venous and sinus thrombosis in women. Stroke. 2009;40(7):2356-61.

6. de Bruijn SF, Stam J, Koopman MM. Case-control study of risk of cerebral sinus thrombosis in oral contraceptive users and in carriers of hereditary prothrombotic conditions. The cerebral venous sinus thrombosis study group. BMJ. 1998;316:589-92.

7. de Bruijn SF, de Haan RJ, Stam J. Clinical features and prognostic factors of cerebral venous sinus thrombosis in a prospective series of 59 patients for the cerebral venous sinus thrombosis study group. JNNP. 2001;70:105-8.

8. Schaller B, Graf R. Cerebral venous infarction: the pathophysiological concept. Cerebrovascular Dis. 2004;18(3):179-88.

9. Bousser MG, Chiras J, Bories J, Castaigne P. Cerebral venous thrombosis: a review of 38 cases. Stroke. 1985;16(2):199-213.

10. Fink JN, McAuley DL. Cerebral venous sinus thrombosis: a diagnostic challenge. Internal Med J. 2001;31:384-90.

11. Guenther G, Arauz A. Cerebral venous thrombosis: a diagnostic and treatment update. Neurologia. 2011;26:488-98.

12. Einhaupl K, Bousser MG, de Bruijn SF. EFNS guideline on the treatment of cerebral venous and sinus thrombosis. Eur J Neurol. 2006;13:553-9.

Cite this article as: Singh A, Nanda S. A case report: venous sinus thrombosis in pregnancy. Int $\mathbf{J}$ Reprod Contracept Obstet Gynecol 2017;6:4721-2. 